\title{
A New Murine Monoclonal Antibody Reports an Activation-dependent Change in the Conformation and/or Microenvironment of the Platelet Glycoprotein IIb/IIla Complex
}

\author{
Barry S. Coller \\ Division of Hematology, State University of New York at Stony Brook, New York 11794
}

\begin{abstract}
Considerable evidence indicates that the glycoprotein (GP) IIb/IIIa complex on human platelets functions as a receptor for fibrinogen, but little is known about the mechanism of receptor "exposure." To investigate this mechanism, our previously described murine monoclonal antibody (10E5) and a new monoclonal antibody (7E3), both of which block the binding of fibrinogen to platelets and bind to GPIIb and/or GPIIIa, were radiolabeled and their rates of binding to native and ADP-activated platelets were studied. At low concentrations, ${ }^{125}$ I-10E5 bound nearly equally rapidly to both native and activated platelets, whereas ${ }^{125} \mathrm{I}-7 \mathrm{E3}$ bound slowly to native platelets and much more rapidly to activated platelets. This increased rate of $7 \mathrm{E3}$ binding is unlikely to be due to an increase in the number of GPIIb/IIIa sites on the surface of activated platelets because: $(a)$ the rate of $10 E 5$ binding was unchanged; (b) the total number of surface GPIIb/IIIa sites increased by only $2-10 \%$ with activation as judged by equilibrium binding of near-saturating concentrations of $10 \mathrm{E5}$ and $7 \mathrm{E3}$, and $(c)$ there was $<1 \%$ release of platelet factor 4 with activation, indicating minimal fusion of $\alpha$-granule membranes (a potential source of GPIIb/IIIa) with the plasma membrane. Other activators (epinephrine, thrombin, and ionophore $\mathbf{A}$ 23187) also increased the rate of 7E3 binding, as did digestion of platelets with chymotrypsin. Aspirin did not affect the rate of binding of 7E3, whereas apyrase, prostaglandin $E_{1}$, and dibucaine all inhibited the enhancement of the 7E3-binding rate produced by ADP. These data provide evidence for an activation-dependent change in the conformation and/or microenvironment of the GPIIb/IIIa complex, and offer a method of studying the receptor exposure mechanism that does not rely on the binding of fibrinogen itself.
\end{abstract}

\section{Introduction}

The binding of macromolecular ligands, most notably fibrinogen, to the glycoprotein IIb/IIIa (GPIIb/IIIa) ${ }^{1}$ complex on the platelet surface after appropriate stimulation must be

This work was presented in part as an abstract to the meeting of the American Society of Hematology, December 1984.

Received for publication 7 September 1984 and in revised form 26 February 1985 .

1. Abbreviations used in this paper: ACD, acid-citrate dextrose; GFP, gel-filtered platelets; GP, glycoprotein; HBMT, Hepes-buffered, modified Tyrode's solution; $P F-4$, platelet factor $4 ; P E_{1}$, prostaglandin $E_{1}$; PRP, platelet-rich plasma.

J. Clin. Invest.

(C) The American Society for Clinical Investigation, Inc.

0021-9738/85/07/0101/08 \$1.00

Volume 76, July 1985, 101-108 crucial for normal platelet function since patients with Glanzmann's thrombasthenia, whose platelet GPIIb/IIIa complex is either deficient or abnormal, have a severe bleeding disorder (1-7). Still unresolved, however, is the molecular mechanism by which agonist activation results in the ability of this complex to bind these ligands, the process commonly termed receptor "exposure." One leading hypothesis is that agonist activation induces a change in either the conformation and/or microenvironment of GPIIb/IIIa such that the ligands can interact with a portion of the complex possessing a high binding affinity, but until now the only way to assess such a change was by inference from the binding of fibrinogen and the other ligands themselves. The present study, employing two different murine monoclonal antibodies, each directed at a site on the GPIIb/IIIa complex, provides independent evidence to support this hypothesis.

\section{Methods}

Monoclonal antibodies. The production, screening, purification, characterization, and iodination of antibody 10E5 have been reported in detail previously (8). The hybridoma cell line producing antibody 7E3 was derived from the same fusion as 10E5. 7E3 culture supernatants were positive in the fibrinogen-coated bead screening assay (8), suggesting the presence of an antibody that blocks the interaction of platelets with fibrinogen. The 7E3 cells were frozen in 10\% dimethylsulfoxide$90 \%$ fetal calf serum soon after the fusion $(7 / 10 / 81)$ and thawed 15 mo later. The cells were subcloned by both the limiting dilution technique (9) and growth in soft agar to insure monoclonality. Antibody was then produced in ascites tumors, and further purified, characterized, and iodinated as reported for 10E5 (8).

Platelet preparation. Platelet-rich plasma (PRP) was prepared by differential centrifugation of blood anticoagulated with 0.01 vol of $40 \%$ trisodium citrate, $0.1 \mathrm{vol}$ of $3.2 \%$ trisodium citrate, or $0.14 \mathrm{vol}$ of acidcitrate dextrose solution (ACD-A). Gel-filtered platelets (GFP) were prepared from PRP by chromatography on a $8 \times 2.5-\mathrm{cm}$ Sepharose 2B (Pharmacia Fine Chemicals, Piscataway, NJ) column, using a modified Tyrode's buffer (HBMT) containing $N$-2-hydroxyethylpiperazine- $N^{\prime}$-2-ethane sulfonic acid (Hepes) and albumin for elution $(0.138$ $\mathrm{M} \mathrm{NaCl}, 2.7 \mathrm{mM} \mathrm{KCl}, 0.4 \mathrm{mM} \mathrm{NaH}_{2} \mathrm{PO}_{4}, 12 \mathrm{mM} \mathrm{NaHCO}, 2 \mathrm{mM}$ $\mathrm{MgCl}_{2}, 0.01 \mathrm{M}$ Hepes, $0.1 \%$ glucose, $0.2 \%$ bovine serum albumin, $\mathrm{pH}$ 7.45) (10). Platelets were counted in an electronic particle counter (Particle Data, Inc., Elmhurst, IL) and aggregation of GFP was performed as previously described (11), with fibrinogen $(2.0 \mathrm{mg} / \mathrm{ml}$; A. B. Kabi, Stockholm, Sweden) being added just before the ADP (Sigma Chemical Co., St. Louis, MO). Platelets from a normal donor and a patient with Glanzmann's thrombasthenia from the Iraqi-Jewish population (12) were washed and solubilized in Triton X-100 for use in radioimmunoelectrophoresis as previously described (13). To assess the EDTA sensitivity of the epitopes recognized by $10 \mathrm{E} 5$ and 7E3, the solubilized normal platelets were incubated with $10 \mathrm{mM}$ EDTA for 30 $\min$ at $37^{\circ} \mathrm{C}$.

Radioimmunoelectrophoresis of solubilized normal, thrombasthenic, or EDTA-treated platelets was performed on premade $1.5 \%$ agarose gels in $35 \mathrm{mM}$ barbital buffer, pH 8.6 (Immunoelectrofilm, Kallestad Laboratories, Inc., Austin, TX) as previously described (13). The 
electrophoretically separated proteins were identified by adding a combination of $0.1 \mathrm{ml}$ of a rabbit antiplatelet serum (DAKO, Accurate Chemical \& Scientific Corp., Westbury, NY) and 220,000 cpm of either radiolabeled $10 \mathrm{E} 5$ or $7 \mathrm{E} 3$ to the troughs and incubating overnight. The proteins precipitated by the heterologous serum were identified by $0.05 \%$ amido black staining and the protein(s) to which the monoclonal antibodies bound were identified by radioautography (XAR-5 film, Eastman Kodak Co., Rochester, NY) as previously described (13).

Antibody binding assay. The platelet preparation (PRP or GFP) was first incubated with buffer, ADP ( $5 \mu \mathrm{M}$ for PRP, $10 \mu \mathrm{M}$ for GFP), or other agonists for $30 \mathrm{~s}$ at $22^{\circ} \mathrm{C}$, and then either a low dose of ${ }^{125} \mathrm{I}$ $10 \mathrm{E} 5$ or ${ }^{125} \mathrm{I}-7 \mathrm{E} 3$ antibody $(0.2-2.5 \mu \mathrm{g} / \mathrm{ml})$ was added for kinetic studies or a high dose of one of the antibodies $(16.5-21.5 \mu \mathrm{g} / \mathrm{ml})$ was added for determining the maximal number of antibody molecules that could be bound. The percentage of antibody bound to platelets was determined at timed intervals for the kinetic studies and after equilibrium was established for the studies to determine the total number of sites ( $30 \mathrm{~min}$ for $10 \mathrm{E} 5$ and $1 \mathrm{~h}$ for $7 \mathrm{E} 3)$. In some experiments performed before it was established that $1 \mathrm{~h}$ was sufficient for equilibrium to be established, incubation with 7E3 proceeded for a longer period of time. Free antibody was separated from bound antibody by layering duplicate $0.1-\mathrm{ml}$ samples over $0.1 \mathrm{ml}$ of $30 \%$ sucrose in a 0.4-ml microcentrifuge tube and centrifuging for $3 \mathrm{~min}$ at $12,000 \mathrm{~g}$ (Beckman Instruments, Inc., Irvine, CA). The tip containing the sedimented platelets was then amputated and both the tip and the supernatant were counted in a gamma spectrometer (Nuclear Chicago, Chicago, IL). Studies to compare the binding affinities of antibodies $10 \mathrm{E} 5$ and $7 \mathrm{E} 3$ and the total number of antibody molecules bound per platelet were performed as described by Trucco and de Petris (14) with correction for the maximum uptake at high concentrations of receptors as they suggested. Nonspecific binding was assessed by adding 111-fold excess cold 10E5 and 7E3 antibody to GFP before adding the radiolabeled antibodies. In most cases $<0.05 \%$, but in no case $>1.5 \%$ of the added radioactivity became associated with the platelet pellet under these conditions, even after $2 \mathrm{~h}$ of incubation. There was no difference in nonspecific binding between buffer- and ADP-treated platelets. Because this level of nonspecific binding was considered insignificant, the data are presented without correction.

Chymotrypsin treatment of platelets. Blood was anticoagulated with 0.01 vol of $40 \%$ sodium citrate containing 0.02 vol of $50 \mathrm{mM}$ acetylsalicylic acid and incubated for $15 \mathrm{~min}$ at $37^{\circ} \mathrm{C}$. PRP was prepared and treated with $0.16 \mu \mathrm{M}$ prostaglandin $\mathrm{E}_{1}\left(\mathrm{PGE}_{1}\right)$ for 20 min at $22^{\circ} \mathrm{C}$, after which $1 \mathrm{M}$ citrate was added to reduce the $\mathrm{pH}$ to 6.3. The PRP was centrifuged at $1,200 \mathrm{~g}$ for $10 \mathrm{~min}$ and the platelet pellet resuspended in the HBMT buffer containing $0.47 \mu \mathrm{M} \mathrm{PGE}_{1}$ and gel-filtered. $\mathrm{PGE}_{1}(0.28 \mu \mathrm{M})$ was added to the GFP, followed by either $0.15 \mathrm{M} \mathrm{NaCl}$ or $\alpha$-chymotrypsin $(35 \mathrm{mg} / \mathrm{ml}$ stock solution, $0.47 \mathrm{mg} /$ ml final concentration; Sigma Chemical Co., type I-S). Incubation proceeded for $15 \mathrm{~min}$ at $37^{\circ} \mathrm{C}$, after which aprotinin (final concentration 3,300 KIU/ml; FBA Pharmaceuticals, New York) was added and the binding studies were performed. In some experiments citrated PRP was gel-filtered without adding acetylsalicyclic acid or PGE $_{1}$, the reaction was stopped by adding a $\times 2.5-50$ excess of phenylmethylsulfonyl fluoride (Sigma Chemical Co.) (which was shown to inhibit $>97 \%$ of the $\alpha$-chymotrypsin protease activity against azocasein) instead of aprotinin and chymotrypsin was removed by washing the platelets in HBMT.

Platelet factor 4 (PF-4) assay. The supernatants of buffer- or ADPtreated platelets from PRP and GFP were assayed for the $\alpha$-granule protein, PF-4, by radioimmunoassay (Abbott Laboratories, North Chicago, IL). To determine the total platelet PF-4, PRP was incubated with $1-2 \mathrm{U} / \mathrm{ml}$ of bovine thrombin (Parke-Davis, Detroit, MI) for $3 \mathrm{~h}$ at $37^{\circ} \mathrm{C}$ and the supernatant serum was assayed.

Affinity chromatography. Approximately $10 \mathrm{mg}$ of purified 7E3 antibody was coupled to $5 \mathrm{ml}$ of Affigel 10 (Bio-Rad Laboratories, Richmond, CA) according to the manufacturer's directions. Platelets from two units of outdated platelet concentrates obtained from the blood bank of University Hospital, Stony Brook, NY, were washed two times in $0.15 \mathrm{M} \mathrm{NaCl}, 0.01 \mathrm{M}$ Tris, $10 \mathrm{mM}$ benzamidine, $1 \mu \mathrm{M}$ $\mathrm{PGE}_{1}, 0.05 \%$ sodium azide, $\mathrm{pH} 7.4$, lysed in $0.15 \mathrm{M} \mathrm{NaCl}, 0.01 \mathrm{M}$ Tris, $20 \mathrm{mM}$ benzamidine, $20 \mathrm{mM} \mathrm{N}$-ethylmaleimide, $100 \mathrm{U} / \mathrm{ml}$ trasylol, $50 \mu \mathrm{g} / \mathrm{ml}$ leupeptin, $10 \mu \mathrm{M}$ D-Phe-Pro-Arg-chloromethyl ketone, $1 \%$ Triton $\mathrm{X}-100,0.05 \%$ sodium azide, $\mathrm{pH} 7.4$, centrifuged to remove platelet debris, and passed over the column. After removal of unbound proteins with $0.15 \mathrm{M} \mathrm{NaCl}, 0.01 \mathrm{M}$ Tris, $20 \mathrm{mM}$ benzamidine, 20 $\mathrm{mM} N$-ethylmaleimide, $1 \%$ Triton $\mathrm{X}-100,0.05 \%$ sodium azide, $\mathrm{pH}$ 7.4 , and $1.5 \mathrm{M} \mathrm{NaCl}, 0.01 \mathrm{M}$ Tris, $5 \mathrm{mM} N$-ethylmaleimide, $0.05 \%$ Triton X-100, pH 7.4, the bound proteins were eluted with $0.05 \mathrm{M}$ diethylamine, $10 \mathrm{mM}$ EDTA, $0.05 \%$ Triton X-100, $5 \mathrm{mM} N$-ethylmaleimide, $0.05 \%$ sodium azide, $\mathrm{pH} 11.5$, and characterized by polyacrylamide gel electrophoresis as previously described (8).

\section{Results}

\section{Characterization of antibody $7 E 3$}

Antibody $7 \mathrm{E} 3$ belongs to the $\mathrm{IgG}_{1}$ subclass. At $10 \mu \mathrm{g} / \mathrm{ml}$ it completely blocks platelet aggregation induced by $5 \mu \mathrm{M}$ ADP. Like antibody 10E5, 7E3 appears to recognize an epitope on GPIIb and/or GPIIla because: $(a)$ it reacts with the same protein in normal platelets as 10E5 as judged by radioimmunoelectrophoresis (Fig. 1); (b) it fails to react with thrombasthenic platelets or platelets in which the GPIIb/IIIa complex is split with EDTA (Fig. 1) (15); and (c) both GPIIb and GPIIIa, identified by their characteristic mobilities in polyacrylamide gel electrophoresis under nonreducing and reducing conditions (8), specifically bound to the affinity column of 7E3 (data not shown). Further support for this identification comes from the quantitative binding studies showing that at saturation the same number of 10E5 and 7E3 molecules bind per platelet (Fig. 2). The antibodies differ somewhat in their apparent affinities (7E3 $=3.4 \mathrm{nM}$ and $10 \mathrm{E} 5=1.2 \mathrm{nM}$ ), but they are of the same order of magnitude. Competitive inhibition studies indicated that the antibodies are directed at different epitopes (16). Thus, binding of saturating concentrations of unlabeled 7E3 did not interfere with the subsequent binding of a subsaturating concentration of radiolabeled 10E5 and the binding of a saturating concentration of unlabeled 10E5 produced only minimal inhibition of the binding of radiolabeled 7E3 (16).

\section{Rate of binding of $7 E 3$ to native and activated platelets}

Gel-filtered platelets. The effect of ADP stimulation on the rate of low-dose ${ }^{125} \mathrm{I}-7 \mathrm{E} 3$ and ${ }^{125} \mathrm{I}-10 \mathrm{E} 5$ binding to GFP is shown in Table I. 10E5 binding was rapid and unaffected by prior stimulation with $10 \mu \mathrm{M}$ ADP, whereas the rate of 7E3 binding to unstimulated platelets was much slower and increased significantly after ADP stimulation. After $1 \mathrm{~h}$, however, the extent of 7E3 binding to unstimulated platelets equaled that for stimulated platelets. When four samples of GFP from the same donor were assayed on different days for the percentage of added 7E3 bound to platelets in $2 \mathrm{~min}$, a consistent difference between buffer- and ADP-treated platelets was observed (buffer $=9.9 \pm 0.7 \%$ [mean \pm SEM], ADP $=34.4 \pm 2.0 \%$; $P<0.001)$. A significant difference between the amount of antibody bound to buffer- and ADP-treated platelets within the first several minutes was apparent over a wide range of 7E3 concentrations, whether expressed as the number of molecules bound per platelet or as the percentage of added antibody contained in the platelet pellet (Table II).

The kinetics of 7E3 binding to unactivated and ADP- 


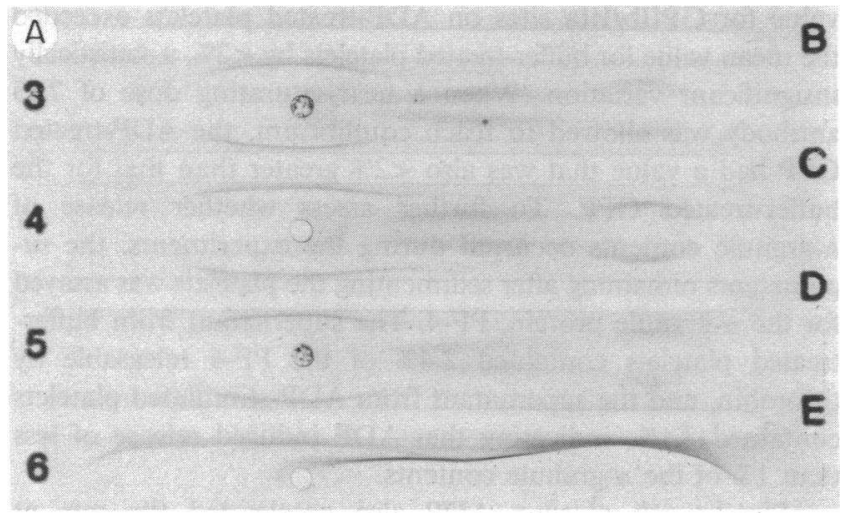

Figure 1. Radioimmunoelectrophoretic analysis of solubilized platelet proteins with a combination of a heterologous antiplatelet antibody and radiolabeled 10E5 or 7E3 antibody. Platelets were solubilized in $1 \%$ Triton X-100 and 3- $\mu$ l samples were electrophoresed in $1.5 \%$ agarose gels as described in the text. Well 3 contained normal platelets, well 4 platelets from a patient with Glanzmann thrombasthenia, and well 5 normal solubilized platelets treated with $10 \mathrm{mM}$ EDTA so as to split the GPIIb/IIIa complex. Well 6 contained normal serum. Arcs were developed by overnight incubation with a combination of

activated platelets were studied in more detail. Equilibrium determinations were deemed unsuitable because the effect of ADP reverses before equilibrium is established (see below), and so it was decided to measure the initial off- and on-rates.

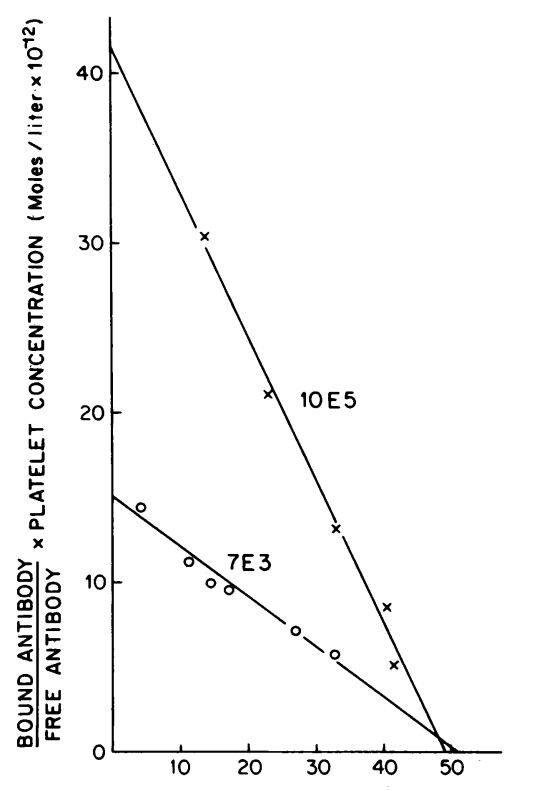

BOUND ANTIBODY (molecules/plotelet $\times 10^{3}$ )

Figure 2. Graphic analysis of the binding of radiolabeled 10E5 and 7E3 to unstimulated platelets. PRP was prepared from citrated whole blood and adjusted to $3.17 \times 10^{11}$ platelets/liter. Triplicate $0.1-\mathrm{ml}$ samples were incubated with varying amounts of the antibodies for 2 $\mathrm{h}$ at $22^{\circ} \mathrm{C}$ and then layered over $0.1 \mathrm{ml}$ of $30 \%$ sucrose and centrifuged to separate platelet-bound antibody from free antibody. Bound antibody was calculated from the bound radioactivity-and the specific activity of the antibodies (185 and $119 \mathrm{cpm} / \mathrm{ng}$ for $7 \mathrm{E} 3$ and $10 \mathrm{E} 5$, respectively). Free antibody was calculated as suggested by Trucco and de Petris (14) from the amount bound and the maximal amount that could be bound at high platelet concentrations (67.5 and 69.5\% of the added radioactivity for 7E3 and 10E5, respectively).

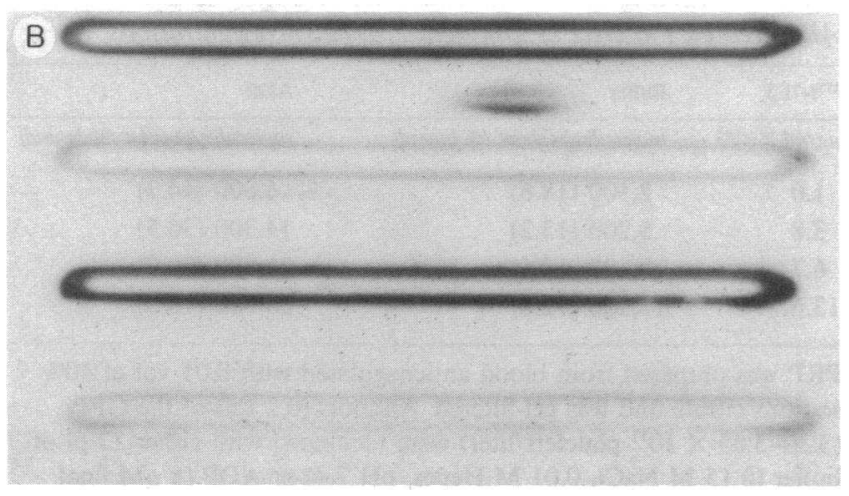

$0.1 \mathrm{ml}$ of rabbit antiplatelet serum and $220,000 \mathrm{cpm}$ of radiolabeled $10 \mathrm{E} 5$ (troughs $B$ and $D$ ) or 7E3 (troughs $C$ and $E$ ). Proteins precipitated by the heterologous antiserum were identified by Amido Black staining $(A)$ and the proteins to which 10E5 and 7E3 bound were identified by autoradiography $(B)$. (A) The multiplicity of precipitin arcs formed with each platelet preparation. (B) Both 10E5 and 7E3 selectively bind to the same protein arc in normal platelets. This arc is missing in thrombasthenic platelets and platelets treated with EDTA, supporting its identification as the GPIIb/IIIa complex.

After $5 \mathrm{~min}$ of incubation of GFP $\left(\sim 3 \times 10^{11}\right.$ platelets/liter $)$ with $0.23 \mu \mathrm{g} / \mathrm{ml}$ of ${ }^{125} \mathrm{I}-7 \mathrm{E} 3$, an excess of cold 7E3 $(100 \mu \mathrm{g} /$ $\mathrm{ml}$ ) was added and the residual platelet-bound ${ }^{125} \mathrm{I}-7 \mathrm{E} 3$ monitored over the next $30 \mathrm{~min}$. Virtually no radioactivity eluted from the platelets during that time, indicating an extremely slow off-rate. Identical data were obtained with ADP-treated platelets. The binding of ${ }^{125} \mathrm{I}-7 \mathrm{E} 3$ in $1 \mathrm{~min}$ could then be used as an indication of the on-rate in that no significant loss of antibody from the platelet would occur in that period of time. Fig. 3 shows the results of one of four similar experiments in which the on rate of binding of ${ }^{125} \mathrm{I}-7 \mathrm{E} 3$ to platelets was shown to be linearly related to the input concentration of antibody up to $\sim 3 \mu \mathrm{g} / \mathrm{ml}$. The on-rate of binding to ADP-activated platelets is more than three times greater than that for unactivated platelets, with second-order rate constants of 6.5 $\times 10^{6} \pm 1.0 \times 10^{6} \mathrm{M}^{-1} \mathrm{~min}^{-1}(\mathrm{mean} \pm \mathrm{SD})$ and $2.03 \times 10^{6} \pm 0.2$ $\times 10^{6} \mathrm{M}^{-1} \mathrm{~min}^{-1}(P<0.001)$, respectively. The slow off-rate of 7E3 binding makes it impossible to measure it accurately before the platelets lose their viability. Without the off-rate, it

Table I. Binding of Antibodies ${ }^{125}$ I-7E3 and ${ }^{125}$ I-10E5 to GFP

\begin{tabular}{|c|c|c|c|c|}
\hline \multirow[b]{2}{*}{ Time } & \multicolumn{2}{|l|}{$7 \mathrm{E} 3$} & \multicolumn{2}{|l|}{$10 \mathrm{E} 5$} \\
\hline & -ADP & +ADP & -ADP & +ADP \\
\hline \multicolumn{5}{|l|}{$\min$} \\
\hline 1 & $250 \pm 20^{*}$ & $780 \pm 60 \ddagger$ & $1,070 \pm 80$ & $1,140 \pm 70$ \\
\hline 2 & $430 \pm 30$ & $1,100 \pm 40 \ddagger$ & $1,380 \pm 80$ & $1,390 \pm 60$ \\
\hline 3 & $540 \pm 40$ & $1,250 \pm 50 \ddagger$ & $1,420 \pm 70$ & $1,420 \pm 60$ \\
\hline 5 & $860 \pm 60$ & $1,620 \pm 80 \ddagger$ & $1,670 \pm 60$ & $1,700 \pm 60$ \\
\hline 30 & $1,820 \pm 80$ & $1,930 \pm 100$ & $1,790 \pm 80$ & $1,720 \pm 80$ \\
\hline 60 & $1,950 \pm 80$ & $1,930 \pm 80$ & $1,840 \pm 80$ & $1,750 \pm 70$ \\
\hline
\end{tabular}

Citrated PRP was gel-filtered and adjusted to 2.7-3.2 $\times 10^{11}$ platelets/liter. Samples of $1.2 \mathrm{ml}$ were incubated with $133 \mu \mathrm{l}$ of buffer or ADP $(100 \mu \mathrm{M})$ for $30 \mathrm{~s}$ and then $4.5 \mu \mathrm{l}$ of ${ }^{125} \mathrm{I}-7 \mathrm{E} 3$ or ${ }^{125} \mathrm{I}-10 \mathrm{E} 5$ (both $52 \mu \mathrm{g} / \mathrm{ml}$ ) was added. Duplicate $0.1-\mathrm{ml}$ aliquots were removed at the indicated times, layered over $0.1 \mathrm{ml}$ of $30 \%$ sucrose and centrifuged at $12,000 \mathrm{~g}$ for $3 \mathrm{~min}$. Results are the mean $\pm S E M$ values of four experiments performed with platelets from three separate donors.

* Values given as molecules per platelet (mean \pm SEM).

$\ddagger P<0.001$ comparing values without and with ADP stimulation. 
Table II. Binding of ${ }^{125}$ I-7E3 Antibody to Buffer- and ADP-treated Platelets at Different ${ }^{125}$ I-7E3 Concentrations

\begin{tabular}{clc}
\hline${ }_{125} \mathrm{I}-7 \mathrm{E} 3$ & Buffer & ADP \\
\hline$\mu \mathrm{g} / \mathrm{ml}$ & molecules/platelet (\% bound) & molecules/platelet (\% bound) \\
1.0 & $2,100(18.6)$ & $5,600(44.2)$ \\
3.8 & $5,200(13.2)$ & $14,300(36.5)$ \\
6.7 & $10,100(14.6)$ & $21,300(30.9)$ \\
13.6 & $17,900(12.8)$ & $25,500(18.2)$ \\
\hline
\end{tabular}

PRP was prepared from blood anticoagulated with 0.01 vol of $40 \%$ sodium citrate and was gel-filtered. Aliquots $(0.2 \mathrm{ml})$ of the GFP (3.30-3.65 $\times 10^{11}$ platelets/liter) were incubated with either $22 \mu \mathrm{l}$ of buffer $(0.15 \mathrm{M} \mathrm{NaCl}, 0.01 \mathrm{M}$ Hepes, $\mathrm{pH} 7.4)$ or ADP ( $5 \mu \mathrm{M}$ final concentration) for $30 \mathrm{~s}$ at $22^{\circ} \mathrm{C}$ and then $20 \mu \mathrm{l}$ of various concentrations of ${ }^{125} \mathrm{I}-7 \mathrm{E} 3$ to achieve the final concentrations indicated above. After $5 \mathrm{~min}$, which is too short a time for equilibrium to be established, duplicate $0.1-\mathrm{ml}$ samples were layered over $0.1 \mathrm{ml}$ of $30 \%$ sucrose and centrifuged to separate free antibody from platelet-bound antibody. Results are the mean values of the duplicate determinations.

is not possible to calculate the $K_{\mathrm{D}}$ for comparison to the $K_{\mathrm{D}}$ determined by the equilibrium method reported above. It was possible, however, to measure both the off-rate $\left(6.3 \times 10^{-3}\right.$ $\left.\mathrm{min}^{-1}\right)$ and the on-rate $\left(8.94 \times 10^{6} \mathrm{M}^{-1} \mathrm{~min}^{-1}\right)$ for $10 \mathrm{E} 5$ binding, giving a calculated $K_{\mathrm{D}}$ of $0.7 \mathrm{nM}$, which is in good agreement with the value of $1.2 \mathrm{nM}$ obtained by the equilibrium method.

In that evidence indicates that there is a separate pool of GPIIb/IIIa associated with $\alpha$-granules that may become exposed on the platelet surface when platelets undergo the release reaction (17), it was possible that the increased rate of 7E3 binding with ADP-induced activation was due to an increase in total membrane-associated GPIIb/IIIa as a consequence of the release reaction. To test for variations in total GPIIb/IIIa sites, buffer- and ADP-treated GFP were reacted with near-saturating concentrations of $10 \mathrm{E} 5$ under equilibrium conditions $(30 \mathrm{~min})$ in seven different experiments. The mean

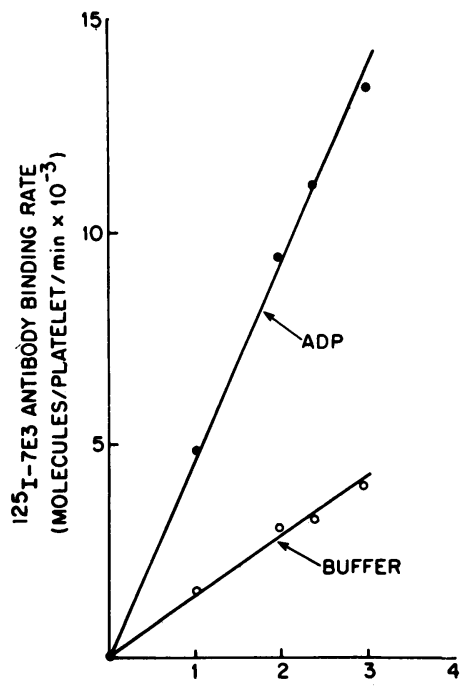

ANTIBODY CONCENTRATION $(\mu g / \mathrm{m})$
Figure 3. Rate of ${ }^{125}$ I-7E3 binding to GFP as a function of 7E3 concentration. Duplicate 0.2-ml samples of GFP $\left(3.19 \times 10^{11}\right.$ platelets/liter) were incubated with $22 \mu \mathrm{l}$ of buffer or ADP (10 $\mu \mathrm{M}$ final concentration) for $30 \mathrm{~s}$ at $22^{\circ} \mathrm{C}$ and then a mixture of unlabeled 7E3 and ${ }^{125}$ I-7E3 (24 $\mu l)$ was added to give the final concentrations indicated. After $1 \mathrm{~min}$, duplicate $0.1-\mathrm{ml}$ samples were layered over $0.1 \mathrm{ml}$ of $30 \%$ sucrose and centrifuged at $12,000 \mathrm{~g}$ for $2 \mathrm{~min}$. The radioactivity in the pellet and supernatant was measured and expressed as molecules of antibody bound per platelet per minute. The mean values for the quadruplicate determinations in one of four similar experiments is shown. value for GPIIb/IIIa sites on ADP-treated platelets exceeded the mean value for buffer-treated platelets by $<2 \%$, a statistically insignificant variation. When a near-saturating dose of 7E3 antibody was allowed to reach equilibrium, the ADP-treated GFP had a value that was also $<2 \%$ greater than that for the buffer-treated GFP. To further assess whether release of $\alpha$-granule contents occurred during the experiments, the supernatants remaining after sedimenting the platelets was assayed for the $\alpha$-granule protein, PF-4. The supernatant from buffertreated platelets contained $2.4 \%$ of the PF-4 releasable by thrombin, and the supernatant from ADP-stimulated platelets contained $3.1 \%$, indicating that ADP induced release of less than $1 \%$ of the $\alpha$-granule contents.

Platelet-rich plasma. ADP also accelerated the rate at which 7E3 bound to platelets in PRP. When 13 samples from seven normal donors were tested for 7E3 binding after a 2-min incubation, buffer-treated platelets bound $18.7 \pm 0.7 \%$ (mean \pm SEM) whereas ADP-treated platelets bound $38.7 \pm 1.3 \%$ $(P<0.001)$. The total number of GPIIb/IIIa sites were found to increase $4.4 \%(n=3)$ upon ADP stimulation when judged by the equilibrium binding of a near-saturating concentration of 7E3 antibody and $10.2 \%(n=8)$ upon using a nearsaturating concentration of $10 \mathrm{E} 5$, values that failed to achieve statistical significance $(P>0.15$ and $>0.1$, respectively). Similarly, supernatant PF-4 in buffer-treated PRP was $1.6 \%$ of the thrombin-releasable PF-4 and the supernatant PF-4 of ADPtreated platelets was $2.5 \%$, indicating $<1 \%$ release by ADP.

Interestingly, when low concentrations of ${ }^{125} \mathrm{I}-10 \mathrm{E} 5$ antibody were incubated with PRP, there was a small, but consistent decrease in the rate of $10 \mathrm{E} 5$ binding $(17 \pm 5 \%$ [mean $\pm \mathrm{SD}$ ]; $n$ $=6)$ when ADP $(5 \mu \mathrm{M})$ was added. Because this was not consistently observed with GFP, one possible explanation is that the ADP-induced binding of fibrinogen to platelets in PRP (but not GFP in that there is no extracellular fibrinogen) slows the binding of $10 \mathrm{E} 5$ because the antibody must displace the already bound fibrinogen (8). Other factors may also be involved, however, inasmuch as in an experiment to test this hypothesis, the addition of $2 \mathrm{mg} / \mathrm{ml}$ fibrinogen (A. B. Kabi) to GFP did not inhibit the binding of 10E5 antibody to ADPtreated platelets to the same extent as was found with PRP (for example, $55 \%$ of the added radioactivity bound to the platelets in untreated PRP in 2 min and $48 \%$ bound to ADPtreated PRP; the comparable values for GFP were 53\% and $52 \%$ and for GFP with added fibrinogen, $54 \%$ and $50 \%$ ).

\section{Correlation between platelet aggregation and the rate of $7 E 3$ binding}

A single preparation of GFP was analyzed for both the initial slope of ADP-induced platelet aggregation and the binding of $7 \mathrm{E} 3(0.2 \mu \mathrm{g} / \mathrm{ml} ; 2 \mathrm{~min})$ at ADP concentrations ranging from 0.15 to $10 \mu \mathrm{M}$. Increasing concentrations of ADP produced both a steeper initial slope of platelet aggregation and more rapid binding of ${ }^{125} \mathrm{I}-7 \mathrm{E} 3$ antibody (data not shown). Interestingly, a dose-dependent change in 7E3 binding could be detected even at subaggregating concentrations of ADP, indicating that the change in $7 \mathrm{E} 3$ binding is more sensitive to ADP stimulation than is the aggregometer response. Increasing the ADP concentration above $10 \mu \mathrm{M}$ produced little or no increase in the rate of 7E3 binding. With PRP, a near-maximal increase in the 2-min binding of 7E3 occurred with $5 \mu \mathrm{M}$ ADP (e.g., in one experiment, the buffer value was 1,220 molecules/platelet, the $5 \mu \mathrm{M}$ ADP value was 2,760 molecules/ 
platelet and the $10 \mu \mathrm{M}$ ADP value was 2,970 molecules/ platelet). The effect of ADP on the rate of 7E3 binding to PRP was apparent as early as $5 \mathrm{~s}$ after stimulation, reached a maximum at $15-30 \mathrm{~s}$, and then slowly decayed over $20 \mathrm{~min}$ (Table III).

\section{Effects of other agonists}

Epinephrine increased the rate of ${ }^{125} \mathrm{I}-7 \mathrm{E} 3$ antibody binding to platelets in PRP in a dose-dependent fashion, but not to the same extent as ADP (Table IV). Epinephrine also produced a slight decrease in the rate of 10E5 binding to platelets, but again epinephrine was less potent than ADP. Both of these data are consistent with previous studies showing epinephrine to be a less potent inducer of fibrinogen binding to platelets than ADP $(18,19)$. As with ADP, epinephrine did not increase the total number of $10 \mathrm{E} 5$ binding sites as measured by a nearsaturating concentration of $10 \mathrm{E} 5$.

Thrombin $(0.5 \mathrm{U} / \mathrm{ml})$ and ionophore A $23187(5 \mu \mathrm{M})$ both caused a greater increase in the 2-min binding of 7E3 to GFP than did ADP (Table IV). The interpretation of these data is complicated, however, in that both agents also significantly increased the total number of 10E5 and 7E3 molecules that could bind to platelets (Table IV). The additional binding sites may be derived from $\alpha$-granule GPIIb/IIIa that becomes associated with the plasma membrane as a result of the induction of the release reaction by these agents (see Discussion).

\section{Effects of inhibitors of platelet function}

Preincubation of PRP with $1 \mathrm{mM}$ acetylsalicyclic acid for 15$20 \mathrm{~min}$ at $37^{\circ} \mathrm{C}$ did not alter the 2-min binding of low doses of 7E3, nor did it inhibit the increase in 2-min 7E3 binding produced by ADP (e.g., in one of three similar experiments, the values for native PRP were $2,140 \pm 90$ molecules/platelet [mean $\pm S D$ ] unstimulated and 5,480 \pm 150 molecules/platelet after ADP stimulation; the comparable values for acetylsalicylic acid-treated platelets were $2,020 \pm 60$ molecules/platelet and $5,330 \pm 180$ molecules/platelet). Apyrase $(2 \mathrm{mg} / \mathrm{ml}$; Sigma Chemical Co.) and $\mathrm{PGE}_{1}(0.1-1.0 \mu \mathrm{M})$, agents known to

Table III. Effect of Prestimulating Platelets with ADP for Various Periods of Time on the Amount of ${ }^{125}$ I-7E3 Bound in 2 min

\begin{tabular}{clcc}
\hline Buffer & & \multicolumn{2}{c}{ ADP $(5 \mu \mathrm{M})$} \\
\hline $5 \mathrm{~s}$ & $1,960^{*}$ & $5 \mathrm{~s}$ & 3,570 \\
$20 \mathrm{~min}$ & 1,720 & $15 \mathrm{~s}$ & 3,740 \\
& & $30 \mathrm{~s}$ & 3,530 \\
& & $1 \mathrm{~min}$ & 3,290 \\
& & $3 \mathrm{~min}$ & 3,210 \\
& & $6 \mathrm{~min}$ & 3,120 \\
& & $10 \min$ & 2,790 \\
& & $20 \min$ & 2,320
\end{tabular}

PRP $\left(2.84 \times 10^{11}\right.$ platelets/liter) was prepared from blood anticoagulated with $0.01 \mathrm{vol}$ of $40 \%$ sodium citrate. Aliquots of $0.2 \mathrm{ml}$ were incubated with $10 \mu l$ of buffer $(0.15 \mathrm{M} \mathrm{NaCl}, 0.01 \mathrm{M}$ Hepes, $\mathrm{pH}$ 7.4) or ADP ( $5 \mu \mathrm{M}$ final concentration) at $22^{\circ} \mathrm{C}$ for the indicated times and then $1 \mu \mathrm{l}$ of ${ }^{125} \mathrm{I}-7 \mathrm{E} 3(0.7 \mu \mathrm{g} / \mathrm{ml}$ final concentration) for $2 \mathrm{~min}$ at $22^{\circ} \mathrm{C}$. Free and platelet-bound antibody were separated by centrifugation of duplicate $0.1 \mathrm{ml}$ samples through $0.1 \mathrm{ml}$ of $30 \%$ sucrose and the amount of antibody bound to the platelets determined.

* Values are given as molecules of ${ }^{125}$ I-7E3 bound per platelet (mean of duplicate determinations).
Table IV. Effects of Various Agonists on the Rate of ${ }^{125} I-7 E 3$ Binding to Platelets and Extent of ${ }^{125}$ I-10E5 Binding to Platelets

\begin{tabular}{lcl}
\hline Agonist & $\begin{array}{l}\text { 125 I-7E3 } \\
(1.0 \mu \mathrm{g} / \mathrm{ml} ; 2 \mathrm{~min})\end{array}$ & $\begin{array}{l}\text { 125I-10ES } \\
(17.9 \mu \mathrm{g} / \mathrm{ml} ; 30 \mathrm{~min})\end{array}$ \\
\hline Buffer & $960^{*}$ & 57,030 \\
ADP $(10 \mu \mathrm{M})$ & 3,790 & 53,570 \\
Epinephrine $(10 \mu \mathrm{M})$ & 2,390 & 53,570 \\
Thrombin $(0.5 \mathrm{U} / \mathrm{ml})$ & 5,540 & 89,860 \\
Ionophore A $23187(25 \mu \mathrm{M})$ & 5,080 & 77,770 \\
& &
\end{tabular}

PRP was prepared from citrated blood $(0.01$ vol of $40 \%$ sodium citrate) and was gel-filtered. The GFP $\left(3.70 \times 10^{11}\right.$ platelets/liter $)$ was then incubated for $30 \mathrm{~s}$ at $22^{\circ} \mathrm{C}$ wtih buffer $(0.15 \mathrm{M} \mathrm{NaCl}, 0.01 \mathrm{M}$ Hepes, pH 7.4), ADP, epinephrine, thrombin, or ionophore A 23187 at the indicated concentrations. Then $4 \mu \mathrm{l}$ of ${ }^{125} \mathrm{I}-7 \mathrm{E} 3$ (final concentration $1.0 \mu \mathrm{g} / \mathrm{ml}$ ) was added at $22^{\circ} \mathrm{C}$ for $2 \mathrm{~min}$ or $20 \mu \mathrm{l}$ of ${ }^{125} \mathrm{I}-10 \mathrm{E} 5$ (final concentration $17.9 \mu \mathrm{g} / \mathrm{ml}$ ) was added for $30 \mathrm{~min}$, after which the amount of antibody bound per platelet was determined.

* Values are given as molecules of antibody bound per platelet (mean of duplicate determinations).

inhibit ADP-induced platelet aggregation, both inhibited the ADP-induced increase in the 2-min binding of ${ }^{125} \mathrm{I}-7 \mathrm{E} 3$ (Table V). They also tended to have a slight effect on the binding of 7E3 to unstimulated platelets, reducing the binding by $\sim 10$ $20 \%$. Dibucaine $(1 \mathrm{mM})$, a local anesthetic that not only inhibits platelet aggregation and release, but also induces morphologic and functional changes in the platelet membrane (20), not only inhibited the ADP-induced increase in the rate of 7E3 binding, but also decreased the rate of 7E3 binding to untreated platelets by $>50 \%$ (Table V).

\section{Effects of chymotrypsin treatment of platelets}

Under the appropriate circumstances, platelets treated with $\alpha$-chymotrypsin can bind fibrinogen and aggregate, even in

Table V. Effect of Platelet-inhibiting Agents on the Binding of ${ }^{125} I-7 E 3$ to Buffer- and ADP-treated Platelets

\begin{tabular}{|c|c|c|}
\hline Agent & Buffer & ADP $(5 \mu \mathrm{M})$ \\
\hline & $\%$ & $\%$ \\
\hline Buffer & $16.2 \pm 0.7 \ddagger$ & $38.1 \pm 0.9$ \\
\hline Apyrase $(2 \mathrm{mg} / \mathrm{ml})(5 \mathrm{~min}$ & 12.4 & 16.2 \\
\hline and $30 \mathrm{~min}^{*}$ ) & (10.5 and 14.2$)$ & (14.5 and 17.8) \\
\hline \multicolumn{3}{|l|}{$\mathrm{PGE}_{1}$} \\
\hline \multirow[t]{2}{*}{$0.1 \mu \mathrm{M}(30 \mathrm{~s}$ and $5 \mathrm{~min})$} & 15.7 & 26.0 \\
\hline & (14 and 17.3) & (25 and 26.9) \\
\hline $1.0 \mu \mathrm{M}\left(30 \mathrm{~min}^{*}\right)$ & 13.8 & 18.6 \\
\hline Dibucaine (1 mM) (5 min) & 7.5 & 10.5 \\
\hline
\end{tabular}

PRP (3.26-3.5 $\times 10^{11} /$ liter) was prepared from citrated $(0.01$ vol of $40 \%$ sodium citrate) blood and incubated at $22^{\circ} \mathrm{C}$ with the indicated agents. ${ }^{125} \mathrm{I}-7 \mathrm{E} 3(0.2-0.72 \mu \mathrm{g} / \mathrm{ml}$ final concentration) was then added and after $2 \mathrm{~min}$ the free and bound antibody were separated. The buffer values are from three experiments, the apyrase and $0.1 \mu \mathrm{M}$ $P E_{1}$ values are the means of two separate experiments (the means of the duplicates from each experiment are given in parentheses), and the other values are the means of duplicates from a single experiment.

* Blood collected into citrate containing the inhibitor.

¥ Percentage of added ${ }^{125}$ I-7E3 bound to platelets (mean \pm SEM). 
the absence of ADP stimulation, suggesting that chymotrypsin digestion directly exposes fibrinogen receptors $(2,21)$. Table VI shows the results of an experiment in which control GFP and chymotrypsin-treated GFP were incubated with low doses of ${ }^{125} \mathrm{I}-7 \mathrm{E} 3$ and ${ }^{125} \mathrm{I}-10 \mathrm{E} 5$ for various periods of time. The chymotrypsin-treated platelets resembled ADP-stimulated platelets in that they bound the 7E3 more rapidly than control platelets; there was no difference in the rate of $10 \mathrm{E} 5$ binding. The increase in the rate of 7E3 binding was apparent even though in this experiment the total number of GPIIb/IIIa sites was reduced by $33.3 \%$ as judged by the equilibrium binding of a near-saturating dose of $10 \mathrm{E} 5$, suggesting some proteolysis of GPIIb/IIIa. Similar data were obtained in other experiments in which $P E_{1}$ was omitted, phenylmethylsulfonyl fluoride was used to inhibit the $\alpha$-chymotrypsin rather than aprotinin, the platelets were washed after digestion, and the time of incubation with $\alpha$-chymotrypsin was reduced so that there was no decrease in the total number of GPIIb/IIIa sites.

\section{Discussion}

Platelets have evolved an extraordinary mechanism that permits them to change rapidly from an unactivated state, in which they do not interact with each other, to an activated state in which they readily aggregate. Considerable evidence supports the idea that platelets develop the ability to aggregate by the "exposure" of receptors associated with the GPIIb/IIIa complex that can bind several different macromolecular, glycoprotein ligands. Fibrinogen is the best-studied ligand, and given its high plasma concentration and the profound platelet function abnormalities found in patients with afibrinogenemia (22-24), the one most likely to contribute to platelet function in vivo. Under the appropriate circumstances, however, von Willebrand factor, thrombospondin, and fibronectin can also bind to the GPIIb/IIIa complex $(5,6,25)$; the contributions of these interactions to clinical hemostasis are less well defined. Among the many agents capable of activating platelets, ADP, epinephrine, thrombin, the calcium ionophore A 23187, and more recently, the proteolytic enzyme $\alpha$-chymotrypsin, have been the most intensely studied.

Table VI. Binding of Antibodies ${ }^{125}$ I-7E3 and ${ }^{125}$ I-10E5 to Control and $\alpha$-Chymotrypsin-digested GFP

\begin{tabular}{cccccc}
\hline & \multicolumn{1}{l}{ TE3 } & & \multicolumn{1}{l}{ 10E5 } & \\
\cline { 2 - 3 } \cline { 5 - 6 } Time & Control & Chymotrypsin & & Control & Chymotrypsin \\
\hline $\min$ & & & & \\
2 & $520^{*}$ & 1,146 & & 1,910 & 1,940 \\
5 & 990 & 2,094 & & 2,510 & 2,580 \\
30 & 3,090 & 4,080 & & 2,860 & 2,830
\end{tabular}

GPP were prepared and treated with $0.5 \mathrm{mg} / \mathrm{ml} \alpha$-chymotrypsin for $15 \mathrm{~min}$ at $37^{\circ} \mathrm{C}$ as described in the text. Aliquots were incubated with $0.5 \mu \mathrm{g} / \mathrm{ml}^{125} \mathrm{I}-7 \mathrm{E} 3$ or $0.4 \mu \mathrm{g} / \mathrm{ml}{ }^{125} \mathrm{I}-10 \mathrm{E} 5$ for the indicated times and then the platelet-bound and free antibody was separated. The total number of GPIIb/IIla binding sites was determined by incubating the platelets with $18.5 \mu \mathrm{g} / \mathrm{ml}$ of ${ }^{125} \mathrm{I}-10 \mathrm{E} 5$ for $30 \mathrm{~min}$. The latter study indicated a $33.3 \%$ decrease in total GPIIb/IIIa sites after $\alpha$-chymotrypsin digestion. Results shown are from one of three similar experiments.

* Values given as molecules per platelet.
The present study employed two different monoclonal antibodies to investigate the mechanism of GPIIb/IIIa receptor "exposure." Both antibodies block the interaction of platelets with fibrinogen, are directed at GPIIb and/or GPIIIa, and fail to react with either glycoprotein alone when platelets are incubated with EDTA at high pH and temperature (15). Since the state of activation induced by ADP is transient, and decays before 7E3 binding reaches equilibrium, kinetic studies of the initial rates of binding of low concentrations of the antibodies were performed rather than equilibrium binding studies. One of the antibodies, 10E5, bound nearly equally rapidly to unactivated and ADP-activated platelets, whereas the other, 7E3, consistently reacted slowly with unactivated platelets and significantly more rapidly with ADP-activated platelets. This same phenomenon occurred with both PRP and GFP. The enhanced rate of 7E3 binding is very unlikely to result from an increase in total GPIIb/IIIa sites on the surface of platelets because: (a) one would expect such a mechanism to also increase the rate of 10E5 binding; $(b)$ only minor changes in the equilibrium binding of near-saturating concentrations of $10 \mathrm{E} 5$ and 7E3 accompanied activation, and (c) evidence for $\alpha$-granule fusion with the plasma membrane (a requirement for the transfer of GPIIb/IIla from the $\alpha$-granule membrane) was minimal as judged by the negligible release of the $\alpha$-granule protein, PF-4. Moreover, acetylsalicylic acid, which does not inhibit the direct effect of ADP in "exposing" fibrinogen receptors on platelets (11), but does inhibit the ADP-induced release reaction, did not inhibit the enhanced rate of $7 \mathrm{E} 3$ binding induced by ADP.

There was a good correlation between the ADP doseresponse curves for changes in the rate of 7E3 binding and the initial slope of platelet aggregation, with 7E3 binding apparently a more sensitive indicator of platelet activation in that it increased even with subaggregating doses of ADP. Whether an assay based on the rate of 7E3 binding will be useful in defining the state of activation of the GPIIb/IIIa receptor mechanism in disease states remains to be determined.

The behavior of other agonists on the rate of 7E3 binding was consistent with their effects on the binding of fibrinogen to platelets. Thus, epinephrine was less potent than ADP (18, 19) and thrombin was more potent (26). Interpretation of the results with thrombin and the other strong agonist, the ionophore A 23187 , is complicated by their exposure of additional GPIIb/IIIa sites, most likely as a result of their inducing the release reaction and the fusion of $\alpha$-granule membrane GPIIb/ IIIa with the plasma membrane. This interpretation is also consistent with the observations that thrombin can expose more fibrinogen binding sites than ADP when maximal doses of both are used $(26,27)$ and that thrombin increases the binding of another monoclonal antibody to GPIIb/IIIa by mobilizing a pool of GPIIb/IIIa that is not on the platelet surface (28). Similarly, the effects of antagonists such as $\mathrm{PGE}_{1}$, apyrase, and dibucaine on the rate of 7E3 binding are consistent with their known effects on ADP-induced fibrinogen binding and/or ADP-induced platelet aggregation (4, 10, 20, 29, 30). The effect of dibucaine was most notable because it not only prevented the ADP-induced increase in 7E3 binding, but also strikingly decreased the rate of 7E3 binding to unstimulated platelets. Thus, it must be operating directly at the membrane level in addition to, or instead of, inhibiting the transduction of the ADP activation signal. Again, this is consistent with both the other membrane effects previously attributed to 
dibucaine (18) and its ability to inhibit markedly the interaction of platelets with fibrinogen-coated beads (4), a reaction that is only slightly inhibited by $\mathrm{PGE}_{1}$. Finally, the correlation between fibrinogen receptor "exposure" and the rate of 7E3 binding was reinforced by the demonstration of a more rapid rate of binding to chymotrypsin-treated platelets than control platelets. It is also in accord with our recent demonstration that GPIIb/ IIIa acts as the fibrinogen receptor on $\alpha$-chymotrypsin-treated platelets (31).

The present study thus provides the first direct evidence that platelet activation results in a change in the GPIIb/IIIa complex. The 7E3 binding assay also permits analysis of the "exposure" of the GPIIb/IIIa fibrinogen receptor independent of measuring fibrinogen binding itself; thus, factors that may alter fibrinogen rather than the receptor are less likely to confound data interpretation. In addition, as shown with dibucaine, it may help to differentiate inhibitory agents that act directly on the receptor from those that act via inhibition of signal transduction.

The molecular basis for the alteration in GPIIb/IIIa that permits ligand binding is still poorly understood. One attractive hypothesis was that GPIIb and GPIIIa are not complexed in unactivated platelets and that platelet activation results in the formation of GPIIb/IIIa heteroduplexes via calcium release. The weight of evidence currently available from studies using monoclonal antibodies that appear to be specific for the GPIIb/ IIIa complex, however, indicates that GPIIb and GPIIIa probably exist as a complex even on unactivated platelets $(15,32-$ 34). Other possibilities include a change in the conformation of the GPIIb/IIIa complex itself or a change in the microenvironment surrounding the GPIIb/IIIa complex. The data from the present study suggest that 10E5 binds to a site on the GPIIb/IIIa complex that is unaffected by the activation process whereas 7E3 binds either preferentially or exclusively with the activated state. This could be due to it exclusively or preferentially recognizing the new conformation of the complex or because the change in the microenvironment permits it to gain access to a GPIIb/IIIa complex that is always in the proper conformation. In that 7E3 does bind, albeit slowly, to unstimulated platelets, there may well be a dynamic equilibrium between the different conformations of the GPIIb/IIIa complex or between the microenvironmental conditions that determine access to the GPIIb/IIIa complex. There are, of course, alternative models, and additional studies will be required to differentiate between the many possibilities.

\section{Acknowledgments}

I want to thank Lesley Scudder and Ann Schwartz for outstanding technical assistance, Shirley Murray and Helen Gabay for outstanding secretarial assistance, and Ellinor Peerschke, Sidonie Morrison, and John Sachs for valuable discussions. Jolyon Jesty was especially helpful in interpreting the kinetic data.

This work was supported by grant 19278 from the National Heart, Lung, and Blood Institute.

\section{References}

1. George N. N., and T. A. Reimann. 1982. Inherited disorders of the platelet membrane. Glanzmann's thrombasthenia and BernardSoulier disease. In Thrombosis and Hemostasis, Basic Principles and Clinical Practice. R. W. Colman, V. J. Marder, E. W. Salzman, and J. Hirsh, editors. J. B. Lippincott, Philadelphia. 296-306.
2. Mustard, J. F., R. L. Kinlough-Rathbone, M. A. Packham, D. W. Perry, E. J. Harfenist, and K. R. M. Pai. 1979. Comparison of fibrinogen association with normal and thrombasthenic platelets on exposure to ADP or chymotrypsin. Blood. 54:987-993.

3. Bennett, J. S., and G. Vilaire. 1979. Exposure of platelet fibrinogen receptors by ADP and epinephrine. J. Clin. Invest. 64: 1393-1401.

4. Coller, B. S. 1980. Interaction of normal, thrombasthenic, and Bernard-Soulier platelets with immobilized fibrinogen: defective platelet-fibrinogen interaction in thrombasthenia. Blood. 55:169-178.

5. Ruggeri, Z. M., R. Bader, and L. DeMarco. 1982. Glanzmann thrombasthenia: deficient binding of von Willebrand factor to thrombinstimulated platelets. Proc. Natl. Acad. Sci. USA. 79:6038-6041.

6. Gralnick, H. R., S. Williams, and B. S. Coller. 1984. Fibrinogen competes with von Willebrand factor for binding to the glycoprotein IIb/IIIa complex when platelets are stimulated with thrombin. Blood. 64:797-800.

7. Ginsberg, M. H., R. Wolff, G. Marguerie, B. S. Coller, R. McEver, and E. F. Plow. 1984. Thrombospondin binding to thrombinstimulated platelets: evidence for a common adhesive protein binding mechanism. Clin. Res. 32:308A. (Abstr.)

8. Coller, B. S., E. I. Peerschke, L. E. Scudder, and C. A. Sullivan. 1983. A murine monoclonal that completely blocks the binding of fibrinogen to platelets produces a thrombasthenic-like state in normal platelets and binds to glycoproteins IIb and/or IIIa. J. Clin. Invest. 72: 325-338.

9. Coller, H. A., and B. S. Coller. 1983. Statistical analysis of repetitive subcloning by the limiting dilution technique with a view toward insuring hybridoma monoclonality. Hybridoma. 2:89-96.

10. Peerschke, E. I., M. B. Zucker, R. A. Grant, J. J. Egan, and M. M. Johnson. 1980. Correlation between fibrinogen binding to human platelets and platelet aggregability. Blood. 55:841-847.

11. Coller, B. S., B. R. Franza, Jr., and H. R. Gralnick. 1976. The pH dependence of quantitative ristocetin induced aggregation: theoretical and practical implications. A new device for maintenance of plateletrich plasma pH. Blood. 47:841-854.

12. Seligsohn, U., and S. Roshoshansky. 1984. A Glanzmann's thrombasthenia cluster among Iraqi Jews in Israel. Thromb. Haemostasis. 52:230-231.

13. Coller, B. S., E. Kalomiris, M. Steinberg, and L. E. Scudder. 1984. Evidence that glycocalicin circulates in normal plasma. J. Clin. Invest. 73:794-799.

14. Trucco, M., and S. de Petris. 1981. Determination of equilibrium binding parameters of monoclonal antibodies specific for cell surface antigens. In Immunological Methods. I. Lefkovits and B. Pernis, editors. Academic Press, Inc. New York. 1-26.

15. Coller, B. S., E. I. Peerschke, A. T. Nurden, and J.-P. Rosa. 1983. The epitope of a monoclonal antibody that inhibits fibrinogen binding to platelets is EDTA-sensitive: implications for the presence of the GPIIb/IIIa complex on unactivated platelets. Thromb. Haemostasis. 50:314. (Abstr.)

16. Coller, B. S., E. I. Peerschke, L. E. Scudder, and U. Seligsohn. 1984. Mapping the platelet fibrinogen receptor with alloimmune and monoclonal antibodies. Circulation. 70:II-195. (Abstr.)

17. Gogstad, G. O., I. Hagen, R. Korsmo, and N. O. Solum. 1981. Characterization of the proteins of isolated human platelet $\alpha$-granules. Evidence for a separate $\alpha$-granule pool of the glycoproteins IIb and IIIa. Biochim. Biophys. Acta. 670:150-162.

18. Peerschke, E. I. 1982. Induction of human platelet fibrinogen receptors by epinephrine in the absence of released ADP. Blood. 60: 71-77.

19. Plow, E. F., and G. Marguerie. 1980. Induction of the fibrinogen receptor in human platelets by epinephrine and the combination of epinephrine and ADP. J. Biol. Chem. 255:10971-10977.

20. Coller, B. S. 1982. Effects of tertiary amine local anesthetics on von Willebrand factor-dependent platelet function: alteration of membrane reactivity and degradation of GPIb by a calcium-dependent protease(s). Blood. 60:731-743. 
21. Niewiarowski, S., A. Z. Budszynski, T. A. Morinelli, T. M. Brudzynski, and G. H. Stewart. 1981. Exposure of fibrinogen receptors on human platelets by proteolytic enzymes. J. Biol. Chem. 256:917925.

22. Gugler, E., and E. F. Luscher. 1965. Platelet function in congenital afibrinogenemia. Thromb. Diath. Haemorrh. 14:361-373.

23. Inceman, S., J. Caen, and J. Bernard. 1966. Aggregation, adhesion and viscous metamorphosis of platelets in congenital fibrinogen deficiencies. J. Lab. Clin. Med. 68:21-32.

24. Weiss, H. J., and J. Rogers. 1971. Fibrinogen and platelets in the primary arrest of bleeding. Studies in two patients with congenital afibrinogenemia. N. Eng. J. Med. 285:369-374.

25. Ruggeri, Z. U., L. de Marco, L. Gatti, R. Bader, and R. R. Montgomery. 1983. Platelets have more than one binding site for von Willebrand factor. J. Clin. Invest. 72:1-12.

26. Plow, E. F., and G. A. Marguerie. 1980. Participation of ADP in the binding of fibrinogen to thrombin-stimulated platelets. Blood. 56:553-555.

27. Peerschke, E. I. B. 1984. Effect of epinephrine on fibrinogen receptor exposure by aspirin-treated platelets and platelets from concentrates in response to ADP and thrombin. Am. J. Hematol. 16:335345.

28. Keller, D. M., M. H. Ginsberg, E. F. Plow, and V. L. Woods. 1984. Thrombin can induce cell surface display of a pool of platelet glycoprotein IIb and IIIa heterodimers distinct from that on the surface of resting platelets. Blood. 64(Suppl. 1):248a. (Abstr.)

29. Mustard, J. F., M. A. Packham, R. L. Kinlough-Rathbone, D. W. Perry, and E. Regoeczi. 1978. Fibrinogen and ADP-induced platelet aggregation. Blood. 52:453-466.

30. Peerschke, E. I., and M. B. Zucker. 1981. Fibrinogen receptor exposure and aggregation of human blood platelets produced by ADP and chilling. Blood. 57:663-669.

31. Peerschke, E. I. B., and B. S. Coller. 1984. A murine monoclonal antibody that blocks fibrinogen binding to normal platelets also inhibits fibrinogen interactions with chymotrypsin-treated platelets. Blood. 64: 59-63.

32. McEver, R. P., E. M. Bennett, and M. N. Martin. 1983. Identification of two structurally and functionally distinct sites on human platelet membrane glycoprotein IIb-IIIa using monoclonal antibodies. J. Biol. Chem. 258:5269-5275.

33. Pidard, P., R. R. Montgomery, J. S. Bennett, and T. J. Kunicki. 1983. Interaction of AP-2, a monoclonal antibody specific for the human platelet glycoprotein IIb-IIIa complex with intact platelets. $J$. Biol. Chem. 258:12582-12586.

34. Brass, L. F., S. J. Shattil, and J. S. Bennett. 1984. Formation of the platelet membrane glycoprotein IIb-IIla complex. Clin. Res. 32: 494A. (Abstr.) 